\title{
The use of temporary internal distraction rods for the correction of severe scliosis
}

\author{
Masatoshi Inoue ${ }^{1 *}$, Hidehisa Torikai ${ }^{1}$, Yoshinori Nakata ${ }^{2}$ \\ From The 10th Meeting of the International Research Society of Spinal Deformities (IRSSD 2014 Sapporo) \\ Sapporo, Japan. 29 June - 2 July 2014
}

\section{Purpose}

Managing patients with scoliosis with curve $>90$ degrees remains challenging. Bruchowski et al reported temporary internal distraction rods (TIDRs) can be used instead of halo traction for severe spinal defmormity. We report 5 cases of severe scoliosis managed with a 2-stage operation using a TIDR.

\section{Patients and methods}

Since 2009, 5 patients were treated with spinal instrumentation with TIDRs. These were 4 female and 1 male patients with a mean age of 28 years (13-55 years) at surgery. Mean preoperative Cobb angle was 116 degrees. All patients had restricted pulmonary dysfunction. For all patients, 2-stage operation using temporary internal distraction was performed. In one case, anterior release followed by 2 -stage operation with a temporary distraction rod was performed.

\section{Results}

Mean postoperative Cobb angle was 39 degrees (22-67 degrees), corresponding to a mean correction rate of $69 \%$ (55-75\%). Mean estimated blood loss was $4024 \mathrm{ml}$, but only one patient required homologous blood transfusion. After first stage operation, CT revealed screw malposition in one patient, but it was removed in 2nd stage operation. We encountered no preoperative complications.

\section{Discussion}

TIDR is an alternative approach in patients undergoing spinal fusion for severe scoliosis. Gradual correction of the spine in 2-stage operation may prevent neurological complications. It decreased the need of homologous blood transfusion.

${ }^{1}$ Chiba Saisei-kai Narashino Hospial, Japan

Full list of author information is available at the end of the article
Authors' details

${ }^{1}$ Chiba Saisei-kai Narashino Hospial, Japan. ${ }^{2}$ Nakata Orthopedic Clinic, Japan.

Published: 19 January 2015

doi:10.1186/1748-7161-10-S1-P25

Cite this article as: Inoue et al:: The use of temporary internal distraction rods for the correction of severe scliosis. Scoliosis 2015 10(Suppl 1):P25.
Submit your next manuscript to BioMed Central and take full advantage of:

- Convenient online submission

- Thorough peer review

- No space constraints or color figure charges

- Immediate publication on acceptance

- Inclusion in PubMed, CAS, Scopus and Google Scholar

- Research which is freely available for redistribution
C Biomed Central 